\title{
ARCHITECTURE IN CROWD FARMS: RELATION BETWEEN HUMAN AND ENERGY
}

\author{
Allaa Shams El-Dien EL-Eshy ${ }^{1}$, Ahmed El-Tantawy El-Maadawy ${ }^{1}$ \\ and Ahmed Abdalla Mohamed Abdalla ${ }^{2}$ \\ ${ }^{1}$ Architecture- Dep. Faculty of Engineering, Mansura University \\ ${ }^{2}$ Architecture- Dep Delta Higher Institute of Engineering and Technolo gy In Mansura
}

\begin{abstract}
The energy problems today combine these issues: much of the world's population has too little energy to meet basic human needs; the monetary costs of energy are rising nearly everywhere; the environmental impacts of energy supply are growing and already dominant contributors to global environmental problems. Confront with global energy problems will require greatly increased investment in improving the efficiency of energy end use and in reducing the environmental impacts of contemporary energy technologies. It will require financing a transition over the next several decades to a set of more sustainable and renewable energy sources. Truth be told, we can see that everyone considers the human is the main reason for many problems, especially which related to energy and environment. In the following paragraph, I'll point out the importance of Life Energy as a solution to energy problems. In streets, malls, buildings, clubs, gym, also at homes. Only by considering the human isn't a reason of wasting energy but is a resource of generating power, from his movement, heat, playing, breathe, from his life as a clean, sustainable and renewable energy resource. The denial that the energy generated from the human body in power plants seems to me to constitute a fundamental misunderstanding about the real human role in the life and society. Human generating power, Start using the thermal and kinetic energy of people in a lot of buildings. To recapitulate, what we have here is an exposition of how we can deal with crowded farms in Egypt as a human power plant to generate life energy. The intriguing ideas expressed here open the door to questions about how we can use the population in solving our problems, can we consider life energy a new renewable source of energy, what is the efficiency of energy generated from the human.
\end{abstract}

\section{Keywords: Crowd Farm; Human Power Plant; Life Energy Architecture; Human Generator; Humanitarian Architecture; Archuman}

\section{INTRODUCTION}

When energy is scarce or expensive, people can suffer material deprivation and economic hardship (John Holdren, 1991). If we didn't find new ways that fail to minimize environmental impacts and political costs, these too can threaten human wellbeing, so the major issues I'll address in this essay are: the global energy problems and pollution which is caused by world's populations, the new methods to find new renewable and sustainable energy resources to tackle energy problems and to suggest new solution to use population areas to generate energy from humans as a resource of energy.

\subsection{Kinds of Current problems}

For economic growth and development, oil prices at a four-year low raise many uncertainties for energy systems across the world. Stagnant growth means lower demand for energy products. At the same time, global production has surged, driven by the shale revolution in the United States, and the reemergence of some markets in the Middle East and North Africa. Lower energy prices will have uneven impacts on importer and exporter countries. Exporters depend on high prices may find it difficult to meet their budgets. Importers may be able to harness the boost to their balance of payments and reduce fuel subsidies, which currently account for a substantial share of many governments' budgets. Policy-makers should tackle the corrosive effects of subsidies, but much more is needed to reduce the distortions that they create across energy markets. 
More than half of the world's population now lives in cities. By 2050, the urban population will have nearly doubled to an estimated 6.4 billion. Most of the increase in urban populations will be in middle- and lower-income countries, which have more limited capacity to manage the new risks being created - and existing risks being exacerbated - by the global urban transition. (WEF_GlobalRisks_Report_2014).

\subsection{Reasons, Impacts and Human Role}

The environmental impacts of energy supply are increasing and already dominant contributors to local, regional, and global environmental problems (including air pollution, water pollution, ocean pollution, and climate change); and the sociopolitical risks of energy supply are growing too. The difficulty of implementing these measures will be greatest by far in the developing countries, for many reasons because of the attendant extra pressures on economic and managerial resources which caused by their high rates of population growth the attendant extra pressures on economic and managerial resources, if efficiency improvements permit delivering the high standard of living to which the world aspires based on a per capita rate of energy use as low as 3 kilowatts, each additional billion people added to the world population will compound these difficulties and increase energy's costs, making everyone poorer.

In Egypt, we have many problems with energy which increasing every day because of population and the other thing which increases the size of the problem the lack of a clear plan to face them, and our inability to use other methods of generating renewable energy. And thus, we can see that everyone considers the human is the main reason for many problems in the world especially in problems related to energy and the environment. Office buildings in both private and public sector need to healthy spaces and high quality of its indoor environment. The Egyptian public office buildings, in other word the Egyptian governmental buildings suffering from many problems on its indoor environment and have poor thermal performance. It consumes about $5977 \mathrm{KWH}$ in the year (2010/2011) which represents $4.6 \%$ of total electricity consumption in Egypt according to the last report of the Egyptian

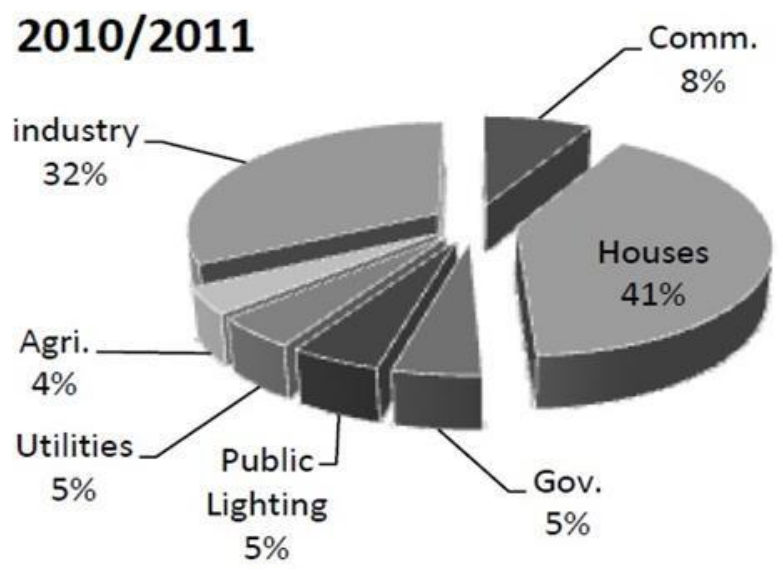

Fig.1. Energy consumption percentage for different sectors in Egypt 2010/2011 Electricity Holding Company (Fig.1) [1].

\subsection{Questions and aims}

Research questions: Can the highest rate of population in Egypt be used as a sustainable and renewable resource of energy in our public spaces!?

Research Aims: Objective of this research is using human power to contribute in saving energy and find new suitable resource of energy which is sustainable and renewable. Using life energy in all public spaces to generate energy.

\section{International Direction}

Over the last two decades, the rise of emerging markets and developing economies has transformed the global economy, and in the process, reshaped the world's energy system. With annual growth rates reaching $7.6 \%$ during the $2000 \mathrm{~s}, 25$ emerging economies grew nine times faster than advanced economies between 2007 and 2014; today, they account for 57\% of global output.26 With $90 \%$ of net energy demand growth until 2035 expected to come from emerging economies, understanding the key trends shaping the energy landscape of these economies offers valuable insights for the future of the global energy system. Energy Savings-Economics and Links to other Policies (WEF_GlobalRisks_Report_2015) [2]. 


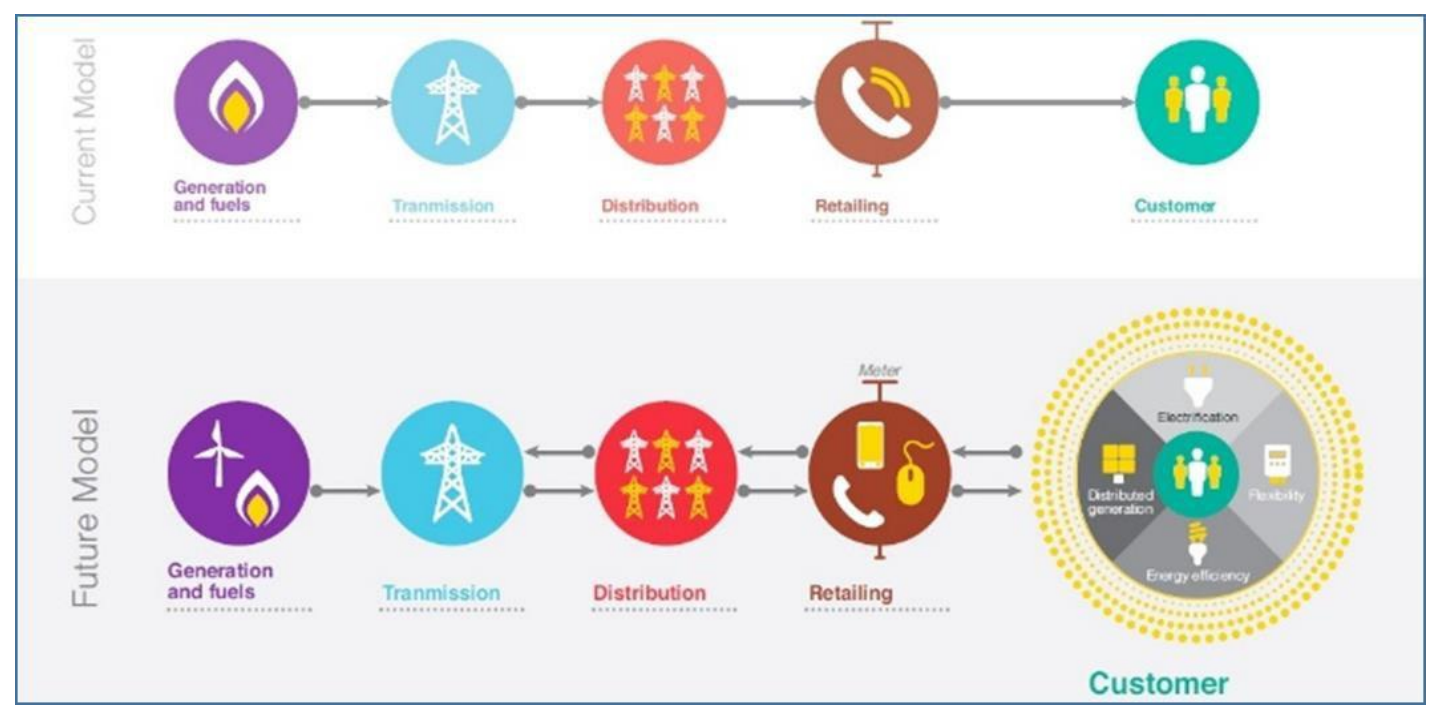

Fig. 2 New business and investment opportunities are emerging close to the customer [2]

\subsection{International experiment}

For environmental sustainability, a few countries have made ambitious pledges, but global emissions trends continue to move in the wrong direction. Advanced economies have made promises to reduce greenhouse gas emissions, and some emerging economies used the United Nations (UN) Climate Summit to pledge to increase the share of renewables in their fuel mix (e.g. India, Mexico) and target emissions (e.g. Indonesia, Malaysia). More recently, the presidents of the United States and China agreed upon a landmark deal to further curb emissions, with the United States increasing its pledge to cut emissions by 2025, and China announcing that it will peak its emissions by or before 2030. Despite these promises, the current landscape still falls short of these targets, and emissions remain on the rise. One unexpected development may prove to have a significant impact on reducing emissions: popular concerns about air quality in major Chinese cities have prompted the government to address air pollution with an array of mitigation measures, at the core of which is a gradual diversification away from coal. While investment in clean energy has grown, much of it relies on subsidies. Their withdrawal, as was the case in Italy, Spain, Greece and the United Kingdom this year, can have a dramatically negative effect; investment has fallen by $74 \%$ in Italy and the United Kingdom as a result [2].

Investment in power generation has grown sharply over the past decade in markets across the OECD, rising from $\$ 60$ billion in 2000 to $\$ 220$ billion in 2012 - an annual growth rate of $11 \%$ in real terms. Most of the investment in generation $(54 \%)$ has been in nonhydro renewables - wind, solar, biomass and geothermal - although it still accounts for only a small percentage (7-8\%) of OECD energy generation (Fig.2) [2].

\subsection{Sustainable and renewable Resources}

Energy reform is required to build future resilience and enable sustained growth. The slowdown in global economic growth is a vivid reminder of the need for structural reforms across many emerging economies, and energy reform is a critical component of this agenda. Effective energy reform should reach beyond immediate imperatives to build capacity for future resilience. This capacity will be tested during times of crisis, and those with the ability to withstand stress will be most prepared to adapt to changing conditions. There is no universally applicable formula for energy reform; each country must develop and implement policies that address its own unique circumstances. Despite this, there are lessons to be learned from successes and failures of other countries to avoid some of the pitfalls of "learning by doing" (Fig.3) [2].

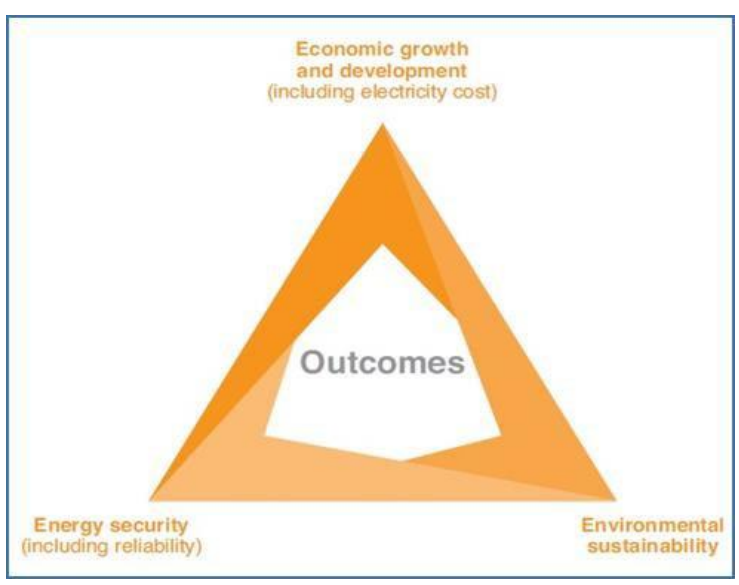

Fig. 3 Energy policy objectives, as applied to electricity 


\subsection{Humanitarian Architecture (Archuman)}

All of the above make the world go to new sources of renewable energy does not depend on other determinants of sunshine or wind speed, and found than in the human energy located largely in human populations (crowd farms), which have no determinants except human existence which is the main reason also for power consumption. Humans are a rich source of energy. An average-sized person stores as much energy in fat as a 1,000-kg battery [12]. People use muscle to convert this stored chemical energy into a positive mechanical work with a peak efficiency of about $25 \%$. This work can be performed at a high rate, with $100 \mathrm{~W}$ easily sustainable [13]. Many devices take advantage of human power capacity to produce electricity, including hand- crank generators as well as windup flashlights, radios, and mobile phone chargers [14]. For electrical power generation over longer durations, it would be desirable to harvest energy from everyday activities such as walking, running, cycling, or even dancing. However, producing substantial energy from these activities is not trivial. And that's which defined as human power plant. Most human powered energy harvesting systems are used to power ubiquitously deployed sensor networks and mobile electronics. These systems scavenge power from human activity or derive limited energy from ambient heat, light, or vibrations. Systems that use human power by walking or running are analyzed,

where an alternative system has been designed, and implemented that generates energy from people dancing in a club environment.

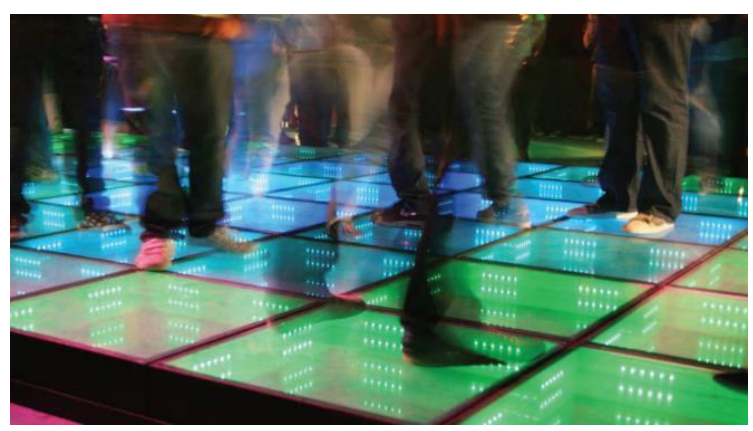

Fig. 4 Sustainable dance floor at the sustainable club Watt in Rotterdam, The Netherlands [3]

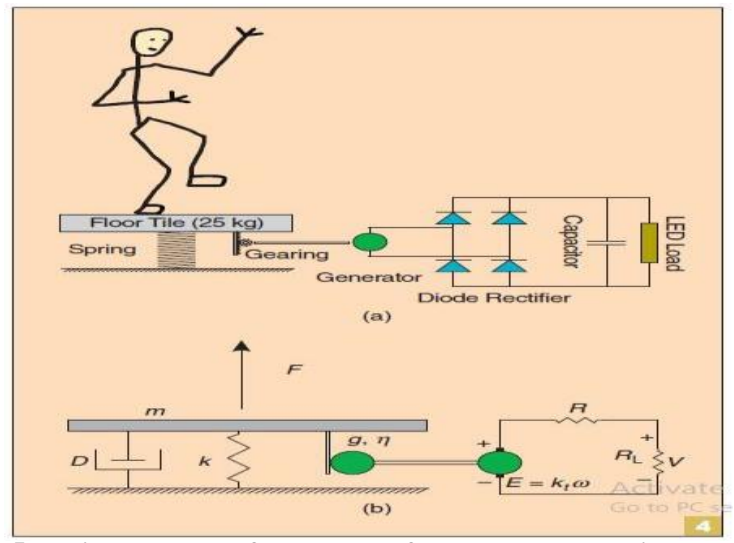

Fig. 5 Equivalent dance-floor model of the energy harvesting illustrating (a) the simple mechanical and electrical model and (b) the schematic of the energy-harvesting part. [4]

Recently, research on energy harvesting has focused on generating electrical power from the shoe sole, with the best devices being generated around $0.8 \mathrm{~W}$ [14]. Alternatively, a spring-loaded backpack [15] has harnessed approximately $7.4 \mathrm{~W}$ of maximum electrical power obtained on the flat during fast walking, using the vertical oscillations of a $38 \mathrm{~kg}$ load. While the backpack does generate significant power levels to other existing devices, the additional degree of freedom provided to the load could impair the user's dexterity and lead to increased fatigue. Harvesting human energy in a club environment would significantly impair comfort since, in this case, the person is situated at the same position, and a non-mobile system has been created to convert the human dancing motion into electrical energy. As such, a system has been researched that generates energy from human dancing in a club environment and directly powers a light-emitting diode (LED) light show situated on the top of the floor tile or around the dancing floor (Fig.4). Harvesting Energy from People as sustainable living gets an increasing foothold in people's lives, unobtrusively tapping some fraction of energy available from human activity has recently gained popularity. In the last few decades, energy harvesting has grown from longestablished concepts into devices, in general, used for powering ubiquitously deployed sensor networks and/or mobile electronics [16]. Recent developments in the field have led to the design of a number of mechanisms that can be used to generate electrical energy from a variety of sources including thermal, solar, strain, and Creating positive energy worldwide inertia (Fig. 5).

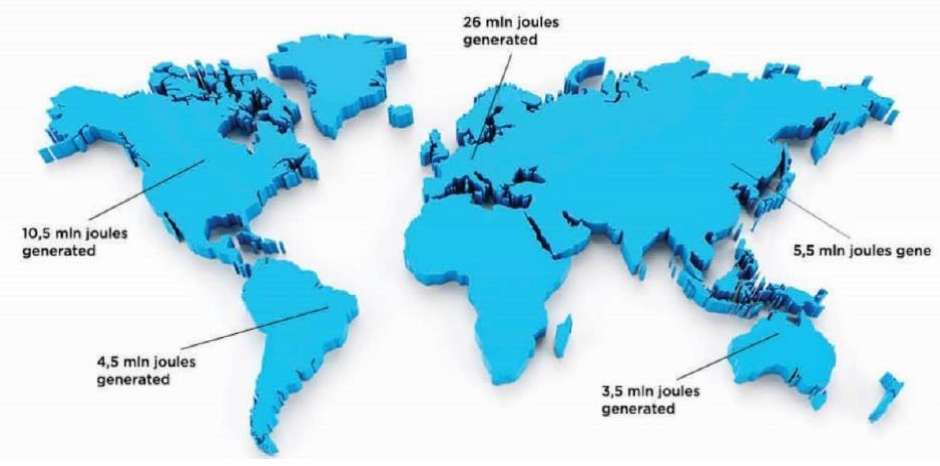

Fig. 6 Illustration which present the amount of power generated from human all over the world according to the official site of sustainable dance Floor Company [5] 


\section{International Examples}

How many people does it take to launch the space shuttle? The answer is $84,162,203$, all of them taking a single step in a Crowd Farming system developed by MIT students James Graham and Thaddeus Jusczyk. Together, they have proposed the creation of a people powered power plant (an idea similar to human-powered gyms, and sustainable dance clubs), in which people would be generating energy by simple act of walking and moving around (Fig. 6).

\section{4,162,203 persons with taking single step = 5 G.W}

Crowd Farm idea would work like this: Boston's South Station railway terminal would house a responsive sub-flooring system made up of blocks that depress slightly under the force of human steps would be installed beneath the station's main lobby. The slippage of the blocks against one another as people walked would generate power through the principle of the dynamo, a device that converts the energy of motion into that of an electric current. The electric current generated by the Crowd Farm could then be used for educational purposes, such as lighting up a sign about energy (Fig. 7). A single human step can only power two 60W light bulbs for one flickering second, but a crowd in motion (Boston South station is an estimated 28,527 steps) and the result is enough energy to power a moving train for one second.

\subsection{Unit (or Device):}

Rotterdam-based company Energy Floors uses an electromechanical system to turn kinetic energy into electricity. Energy Floors was founded in 2007 in the Netherlands and has developed a patented technology creating energy generating floors. The floors are combined with custom made Energy Experiences: a unique invention that captures energy from the public and makes it visible. More than 300 temporaries and 20 permanent installations have been realized over the past five years for a long list of respected clients in more than 20 countries.

In 2008, Energy Floors successfully launched the world's first energy generating dance floor: The Sustainable Dance Floor (SDF) (Fig.8). Next to generating 8 billion joules up to today, the SDF realized fun and awareness regarding energy. The latest development is a pedestrian floor which is the most efficient converter of human footfall into electricity: The Sustainable Energy Floor (SEF). Patents are granted in Europe and the U.S.A.

\subsubsection{The Sustainable Energy Floor (SEF)}

General data: The Sustainable Energy Floor (SEF) is designed especially for permanent installations in high footfall areas. Customized appearance combined with individual control per module creates a high profile floor with great impact. Energy Floors is preparing permanent projects in places like shopping centers, offices, airports, train stations, pavements, fitness centers, parking garages etc. People will be able to generate their own energy that illuminates the space surrounding them, just by walking (Fig.9).

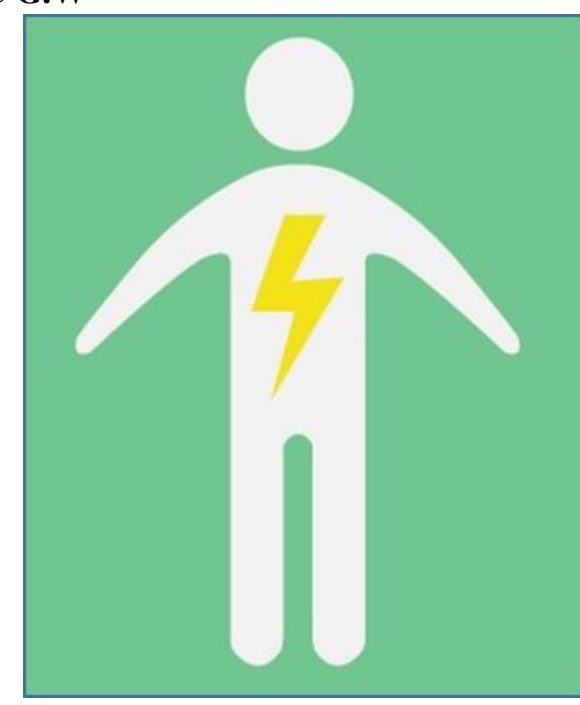

Fig. 7 Communergy, how might we create a physical connection between people and their electricity in order to make renewable energy usage a personal and

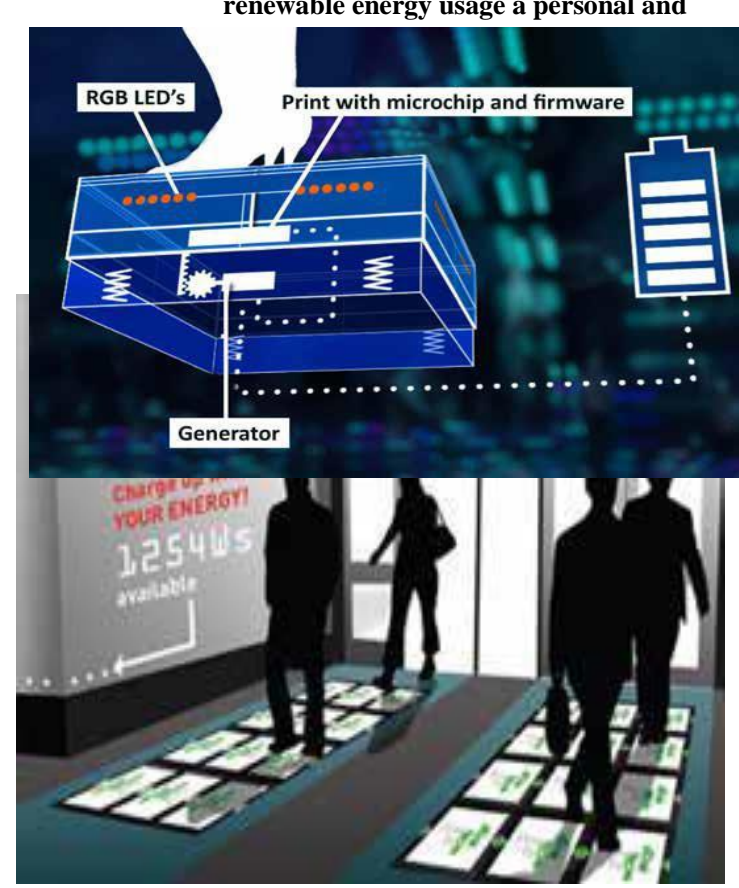

Fig. 9 Illustration explain using SEF in entrances [5] 
Main idea: Their Sustainable Energy Floors are designed for areas with high footfall, such as shopping malls, sports arenas and airports. Each step onto a tile can generate between two and 20 joules of energy, which can be used to power nearby lights or signage.

Application Method: The size of each tiles are 500x500x100 $\mathrm{mm}$. The center of the module $(450 \times 450 \mathrm{~mm})$ can be made from different materials such as recycled ceramics, recycled rubber, synthetic materials, glass or bamboo. A strong but flexible rubber seal completely seals the module. It is waterproof up to IP65. The housing is made from very strong stainless steel. Even when secured to the floor, the module can be opened from the top and can be removed for maintenance. The SEF modules, when regularly maintained as described our service contract, have an expected life time of minimum 15 years. SEF set for use on top of existing flooring. Instead of a frame, a ramp can be applied. The tiles can also be integrated in the surrounding flooring (Fig.10).

Results: The design of the center can be further customized. The colored elements can light up as a form of interaction whenever someone steps on the module. Different set ups and designs are possible, as well as various ways of lighting up the LED panels (slowly, intense, fading, etc.). Here a few examples are being displayed in what way the surface of a Sustainable Energy Floor (here containing of 36 tiles) can be used to create a bigger visual effect. It is also possible use to evenly laminated tile-space (Fig.14).

\subsubsection{The Sustainable Dance Floor (SDF)}

- General data: The Sustainable Dance Floor (SDF) fully customized audiovisual applications connected to the floor create a user experience and reflect the clients' vision and ambitions regarding sustainability. This interactive tool has been a pitch winning concept for events of many well- known creative agencies and brands. Being fully modular, the Sustainable Dance Floor allows for a large amount of possible sizes, shapes and setup designs. The experience can be completely customized in order to fit any of the client's wishes.

- Main idea: Its Sustainable Dance Floor uses the movement of dancers to light up the ground beneath their feet. The interactive light show was designed to raise awareness of the potential of kinetic energy, and has proved popular for corporate and public events, but they have since developed a new product with more practical benefits (Fig.11).

- Application Method: Tile compression when stepped, danced or jumped on, the floor tiles are compressed by $10 \mathrm{~mm}(0.4 \mathrm{in})$ before springing back up again when the pressure's off. Generating power from the vertical movement of the floor tile drives a small internal generator (Fig.12). Smart floor using electricity from the generator powers a microchip, which in turn controls the LED lights within the floor tile. Light show from the LED lights give visual feedback that the dancer's movements are generating electricity and creates a groovy light show. Power output: each $75 \times 75 \times 20 \mathrm{~cm}(30 \times 30 \times 8 \mathrm{in})$ tile can produce up to $35 \mathrm{~W}$ of sustained electricity output, with 5-20W produced by each person. Excess power: Any extra electricity created can be fed back into the power grid or used to power interactive signage.

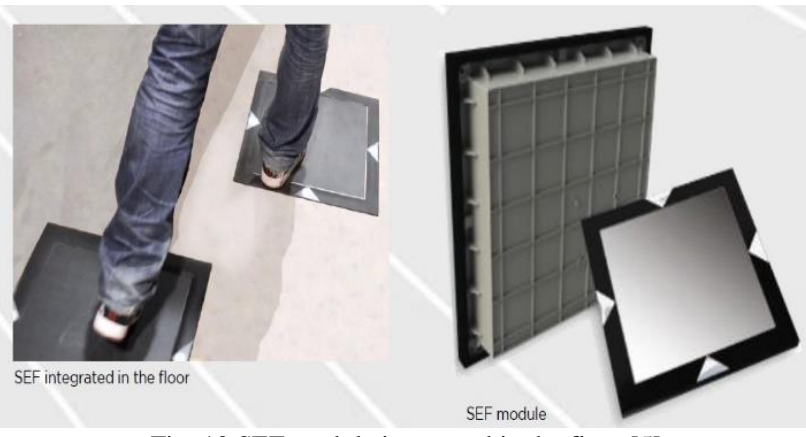

ig. 10 SEF module integrated in the floor [5]

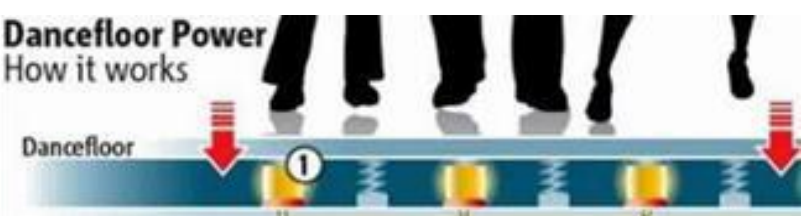

1 Nightclub is fitted with a 'bouncing' 2 The blocks made from crystals produce 2 The blocks made from crystals produce
small electrical current when squashed.

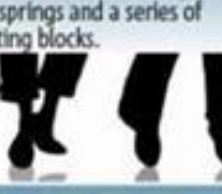
a process known as plezoelectricit
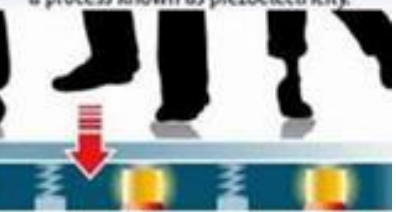

3 As dancers move up and down, the 4

4 The batteries are constantly recharged by the movement of the floor, and used o power parts of the nightclub.

SDF work [5]

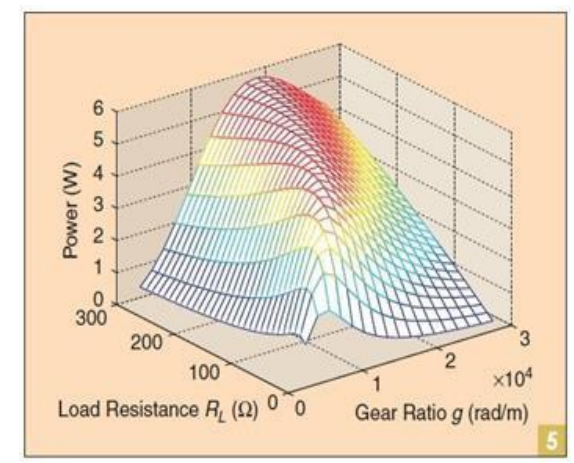

Fig. 12 Output power as a function of the load and gear ratio. [5]

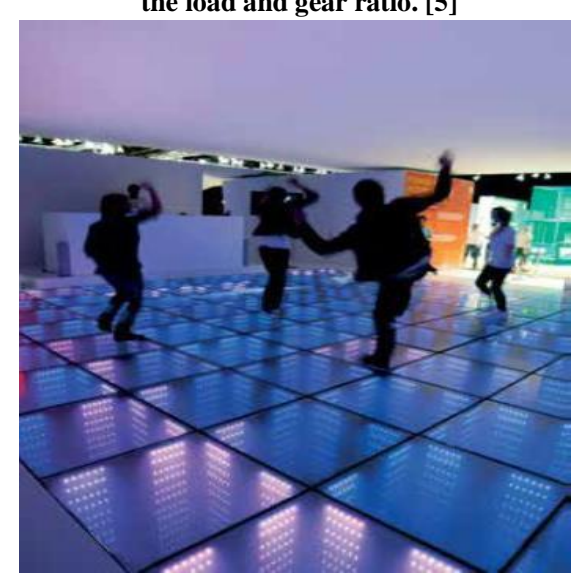

Fig. 13 The Sustainable Dance Floor (SDF) 
ARCHITECTURE IN CROWD FARMS: RELATION BETWEEN HUMAN AND ENERGY

[5] 
- Results: Every module can produce up to 15 watts (with peaks up to 25 watt) and it is possible to connect up to 160 dance floor modules to one controller system. The Sustainable Dance Floor can directly power other equipment. There are some restraints: every module produces up to $15 \mathrm{~W}$ of sustained power per module. You can power other equipment but you will need twice the amount of modules. So for example if your equipment requires $150 \mathrm{w}$, you need $2 \mathrm{x}(150 \mathrm{~W} / 15 \mathrm{~W})=20$ modules (Fig.13).

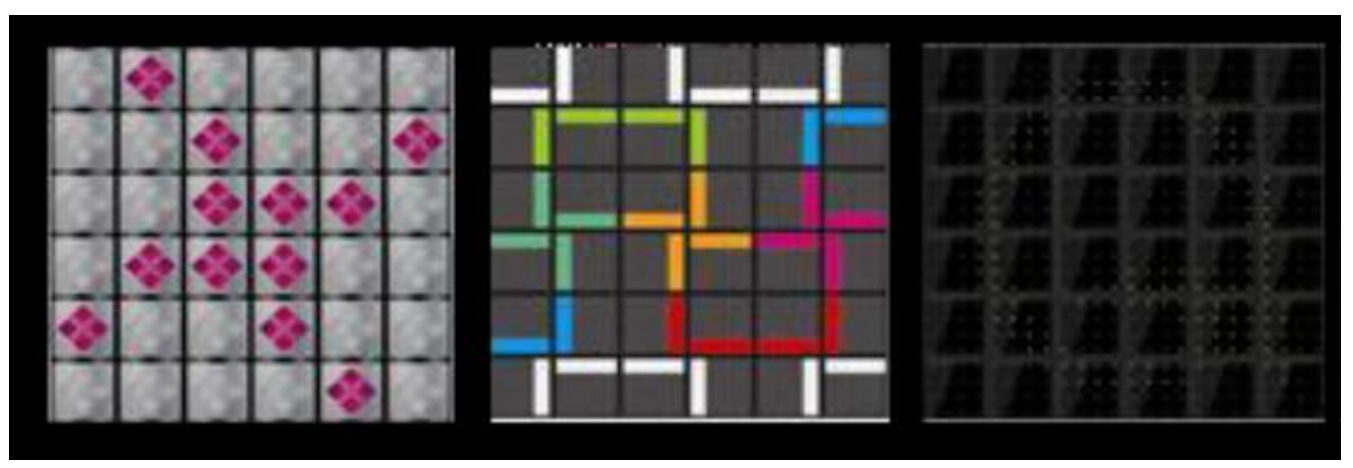

Fig. 14 Few examples are being displayed in what way the surface of SEF (36 modules) [5]

\subsection{Indoor (or Building)}

\subsubsection{Energy-Generating Floors to Power Tokyo Subways}

- General data: When the East Japan Railway Company (JR East)

- Main idea: Piezoelectric flooring is a technology with a wide range of a tourist attraction (Fig.15).

- Results: JR East has been trialing these systems for the past year. They (Fig.16). decided to invest in alternative energy sources, it only had to look to its users for the perfect source of energy. Recently the company decided to update their Tokyo Station with a revolutionary new piezoelectric energy generating floor. The system will harvest the kinetic energy generated by crowds to power ticket gates and display systems (Fig.17). applications that is slowly being adopted in the race to develop alternative energy sources. After all, human power is readily available in pretty much any area with heavy foot traffic, such as a dancefloor, or have recently improved and expanded the system by changing the floor covering from rubber to stone tiles, and have improved the layout of the mechanisms to improve energy generation. The total amount of floorspace will add up to around 25 square meters, and they expect to obtain over $1,400 \mathrm{kw}$ per day - more than enough to power their systems

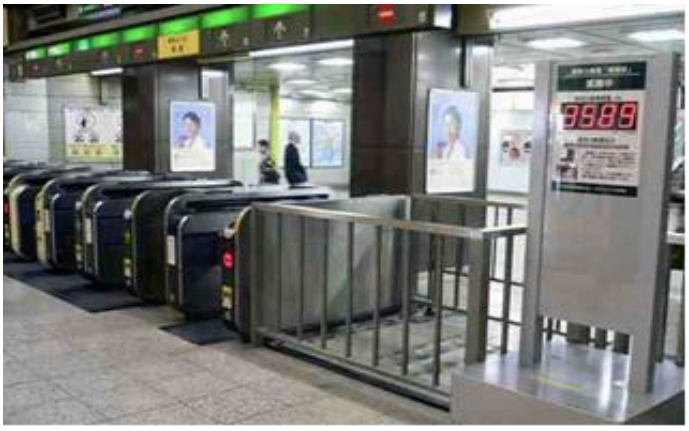

Fig. 15 Ticket gates and display systems in Tokyo Station [6]

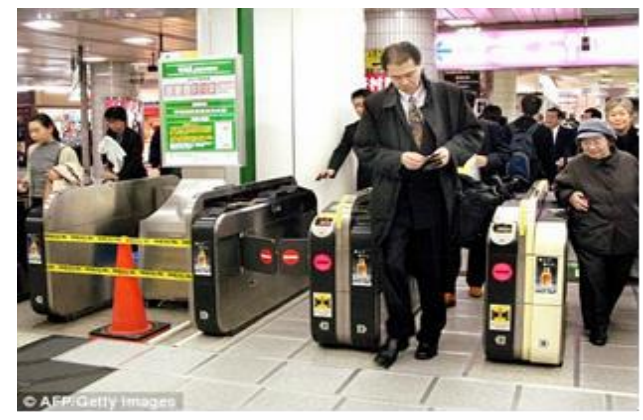

Fig. 16 Tokyo Station with a revolutionary new piezoelectric energy generating floor [6]

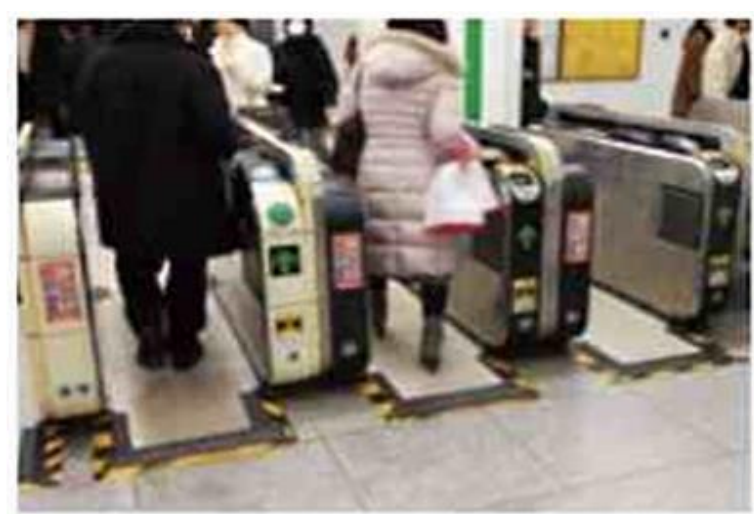

Demonstration experiment at Tokyo Station

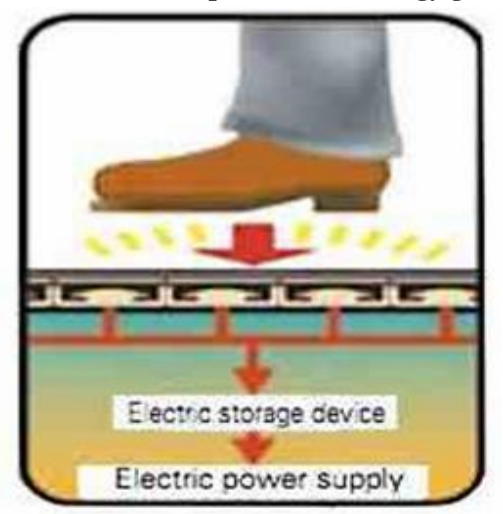

Mectan ism of the power generating fioor

Fig. 17 Piezoelectric energy generating floor harvest the kinetic energy generated by crowds [6] 


\section{ARCHITECTURE IN CROWD FARMS: RELATION BETWEEN HUMAN AND ENERGY}

\subsection{Outdoor (or Urban Spaces)}

\subsubsection{Westfield Stratford City Shopping Centre}

- General data: more than 30 million shoppers per a year, the Westfield Stratford City Shopping Centre has plenty of foot traffic. The mall plans to install a grid of Pavegens in a main crossing outdoors between the shopping Centre and the London Main Stadium, which is known as the heaviest trafficked area the grid will generate power the entire mall's lighting system (Fig.19).

- Main idea: The Pavegen floor tiles flex a slight 5 millimeters when stepped on, capturing kinetic energy which is either stored in lithium polymer batteries beneath its surface or converted into 2.1 watt-hours of electricity and distributed throughout surrounding lights.

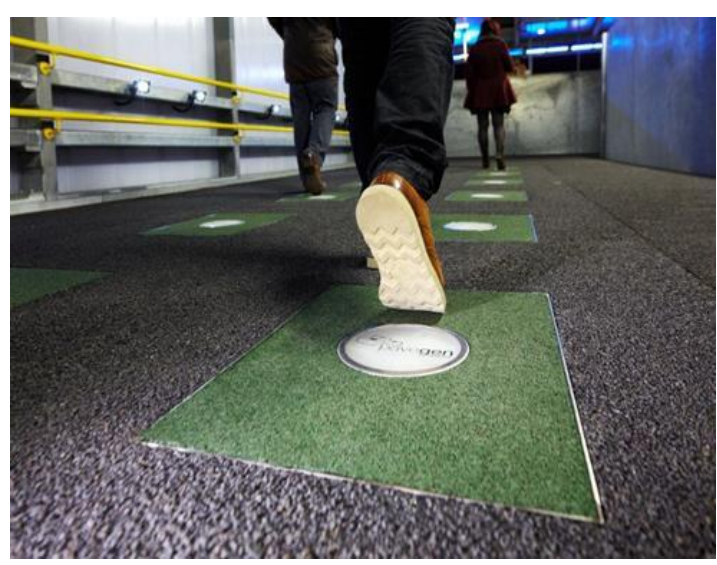

Fig. 18 The Pavegen Floor Tiles [7] The first designs were aimed at illuminating small spaces like bus stops, ticket machines, refrigerators, and shop signs, but with a large number of Pavegens, the possibilities are nearly limitless [7].

- The tiles specifications: The Pavegen tiles themselves are completely eco-friendly. The entire casing is made of marine grade stainless steel and recycled polymer with low carbon concrete. The top surface is built entirely of old truck tires that are not only a great use of recycled material, but also make the tiles incredibly durable throughout years of weather and wear. Even the manufacturing of the Pavegens is kept within 200 miles of the company's main office, reducing energy wasted through transportation and assembly (Fig.18).

- Results: After winning the Big Idea category of the U.K.'s Observer Ethical Awards earlier this year, Kembell-Cook is now in the running to win the Shell Livewire Young Entrepreneur of 2011 Award which would give him 10,000 £ to use towards his invention (Fig.20).

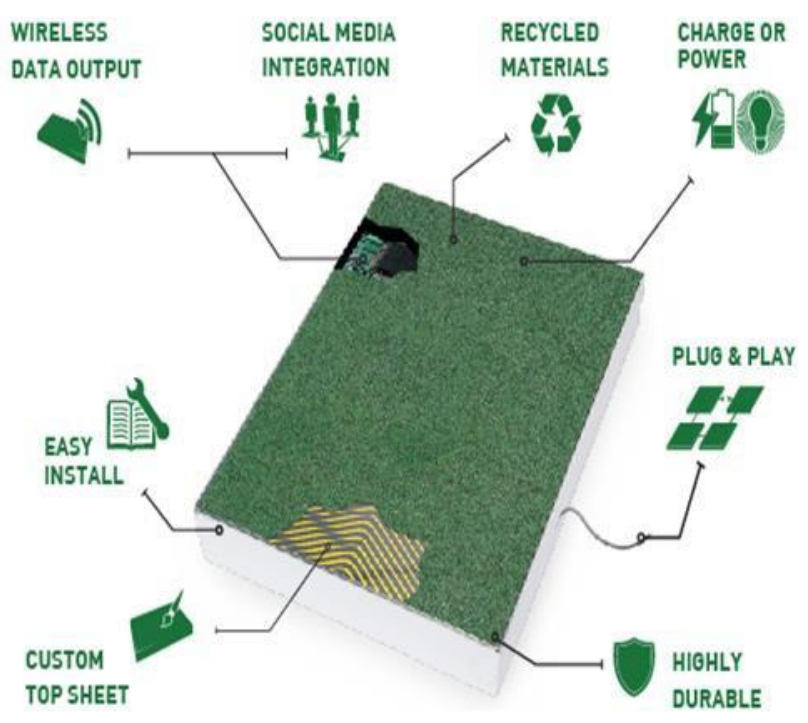

Fig. 20 The Pavegens tiles details [8]

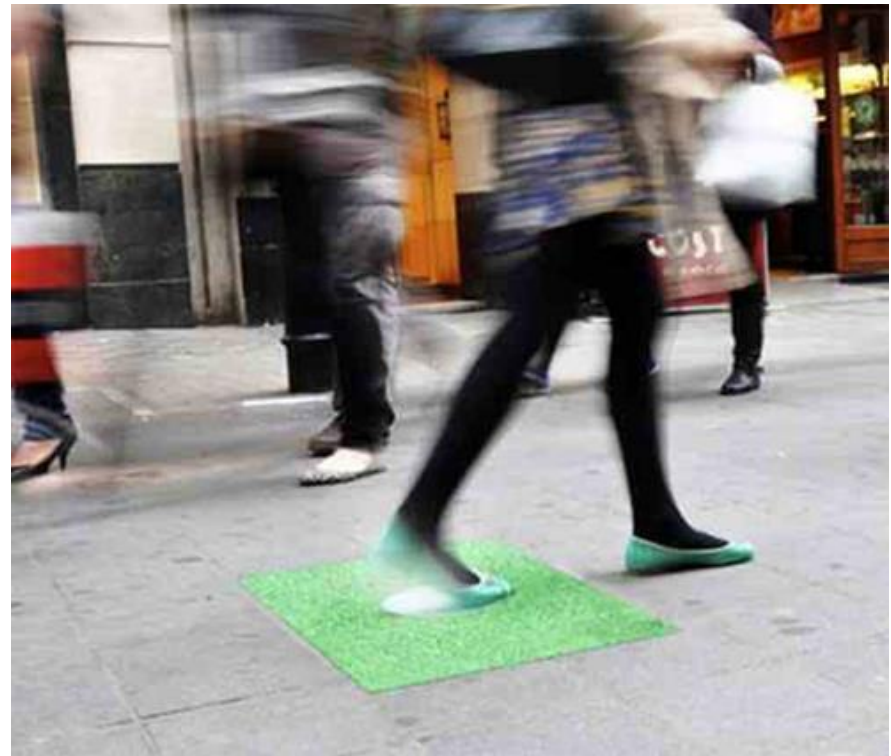

Fig. 19 Pavegens in a main crossing outdoors between the shopping Centre and the London [7]

\subsubsection{New Piezoelectric Railways Harvest Energy from Passing Trains}

- General data: Piezoelectric technology generates energy from pressure and stress on certain surfaces, and we've seen it harvest electricity from roads and dance floors to power lights and signs. Recently Israeli company Innowattech unveiled a new use for this versatile energy tech. They're planning to install piezoelectric pads throughout the country's railways to generate electricity (Fig.21). 
- Main idea: The Company has previously used piezoelectric pads on Israeli highways, and now they're using similar (albeit larger) devices on railways. Innowattech plans on substituting 32 standard railway pads with their own piezoelectric IPEG PADS, which are of a similar design. In addition to generating energy, the new IPEG pads can determine the size of the wheel that passes over them, as well as the speed and weight of the vehicle. A prototype of the energy-generating system was installed last year by the Technion University and Israel Railways in order to show the benefits of the technology (Fig.22).

- Results: The project discovered that a railway track with trafficked by 10 to 20 ten-car trains could produce as much as $120 \mathrm{kWh}$, which could be used to power infrastructural systems such as signs and lights. Any surplus energy would then be uploaded to the country's power grid (Fig.23).

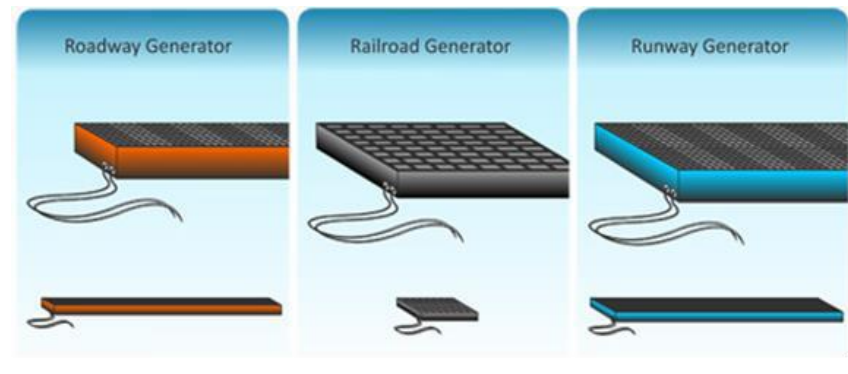

Fig. 22 Different types of piezoelectric pads [9]

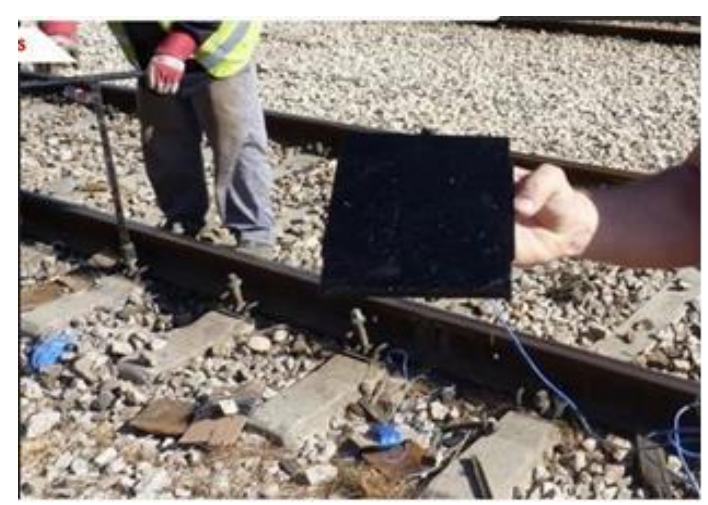

Fig. 21 Piezoelectric pads [9]

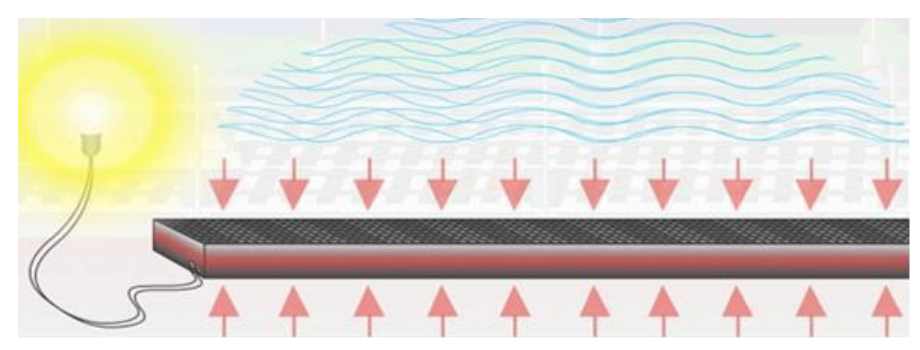

Fig. 23 Concept of Piezoelectric pads [9]

\section{Case Study (Main Entrance for Mansoura University "El-Baron Gate")}

- Mansoura University was founded in 1972 in Mansoura city, Egypt. Mansoura is located at the middle of the Nile Delta in Egypt. It is one of the biggest Egyptian universities and has contributed much to the cultural and scientific life in Mansoura and Egypt. The faculty of medicine was founded in 1962 as a branch of Cairo University. In 1972, a presidential decree announced the establishment of the University under the name "East Delta University". Later on, its name was changed to Mansoura University in 1973 (Fig.24, 25, 26).

More than 150.000 persons dealing with Mansoura University in different sectors (Faulty members, undergraduates, postgraduates ...etc.) according to official site of the university. By dividing this number on the five main entrances of the university, that's mean we have an average more than 30.000 persons per entrance.

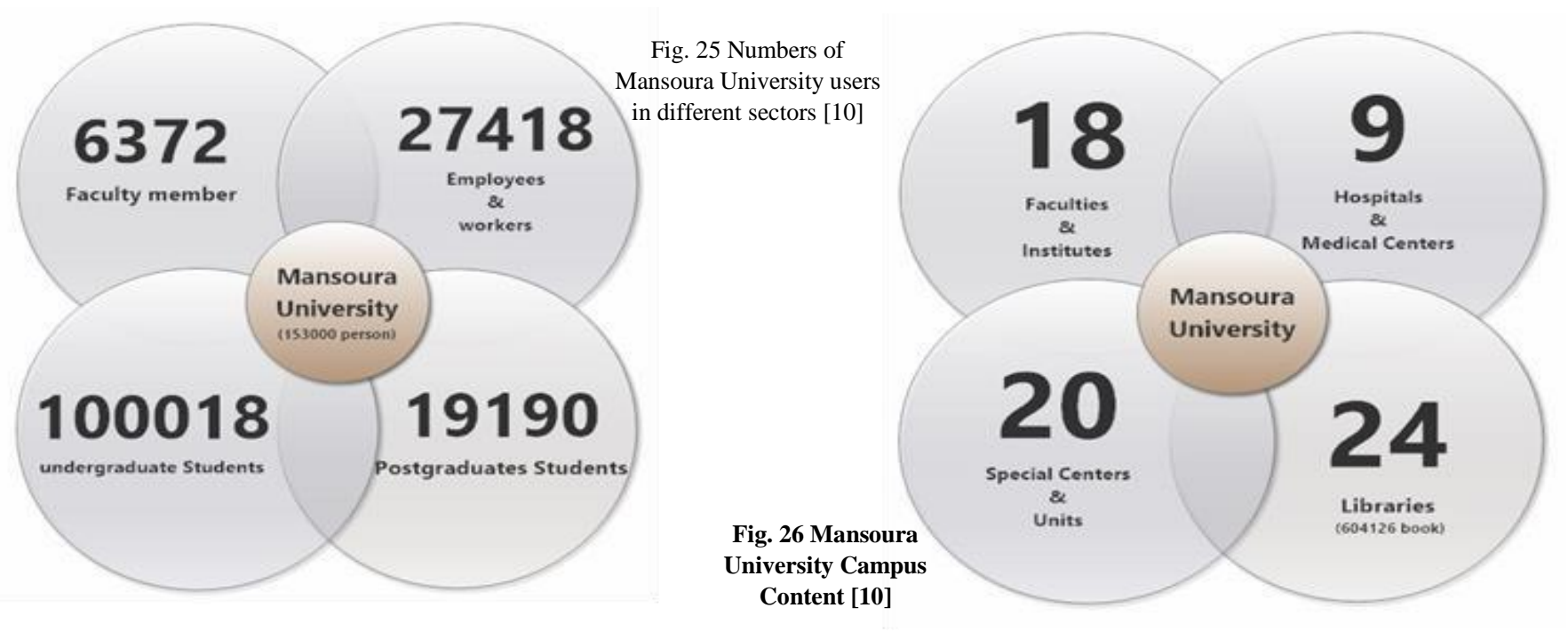


In this paper we took the main entrance which called "El-Baron Gate" to apply our ideas on it. And making suggestion solutions in design and urban of this area to generate power from this huge number of people which crossing this gate every day (Fig.27, 28, 29, 30).

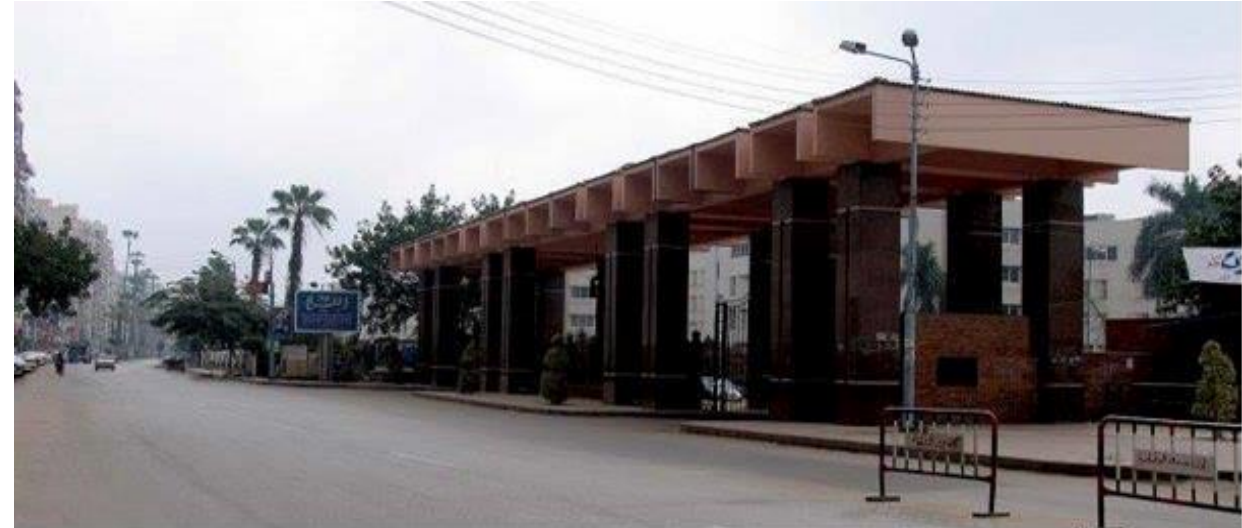

Fig. 27 Main Entrance for Mansoura University “El-Baron Gate” (Real Photo)

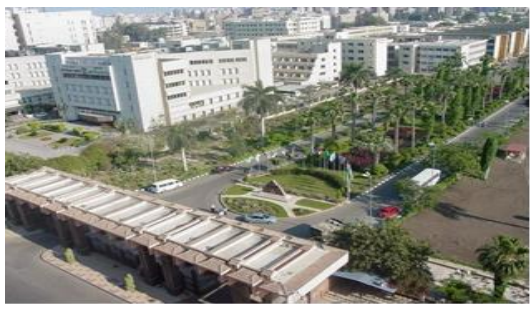

Fig. 28 "El-Baron Gate" (Real Photo)

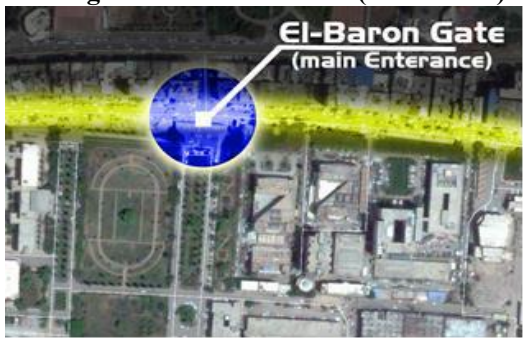

Fig. 29 "El-Baron Gate" (Real Photo from Google Earth)

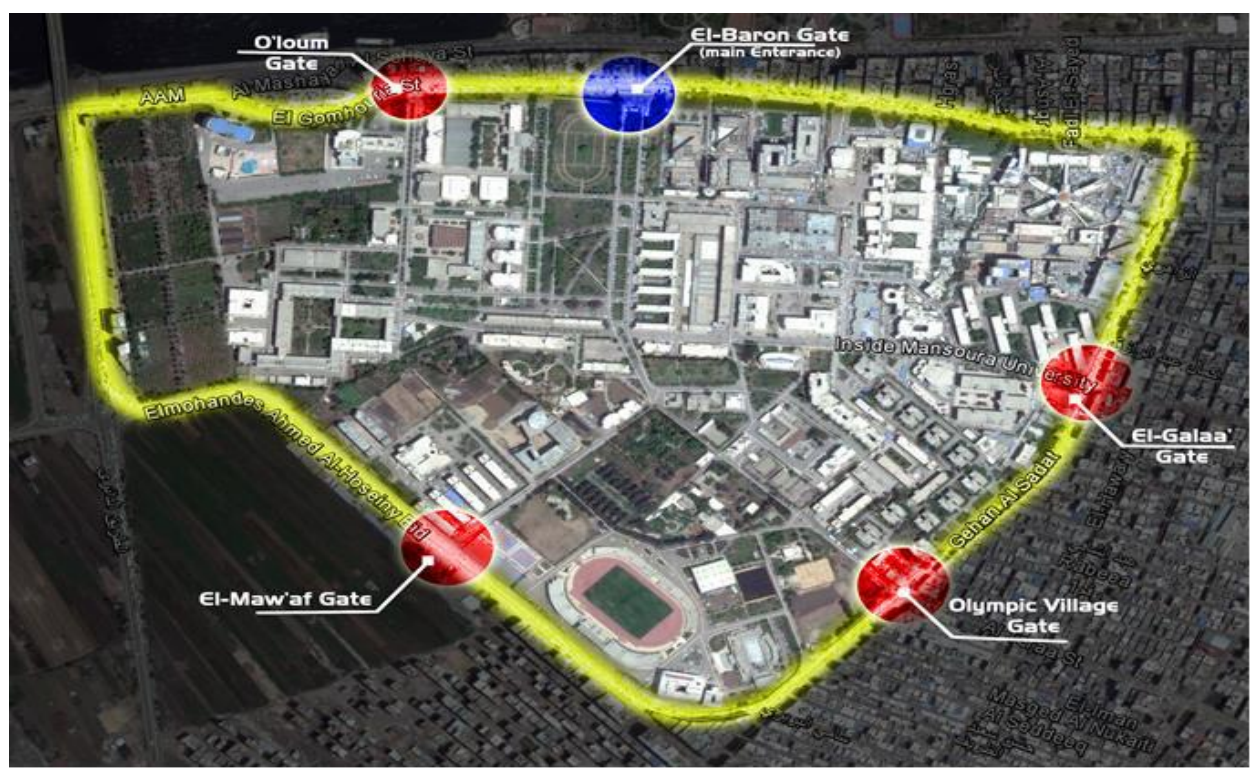

Fig. 30 Outline of Mansoura University Campus (Real Photo from Google Earth)

We are dividing "El-Baron Gate" to four study zones:

- Zone (A): Pedestrian entrance

- Zone (B): Car entrance

- Zone (C): Entrance lobby

- Zone (D): Footpath

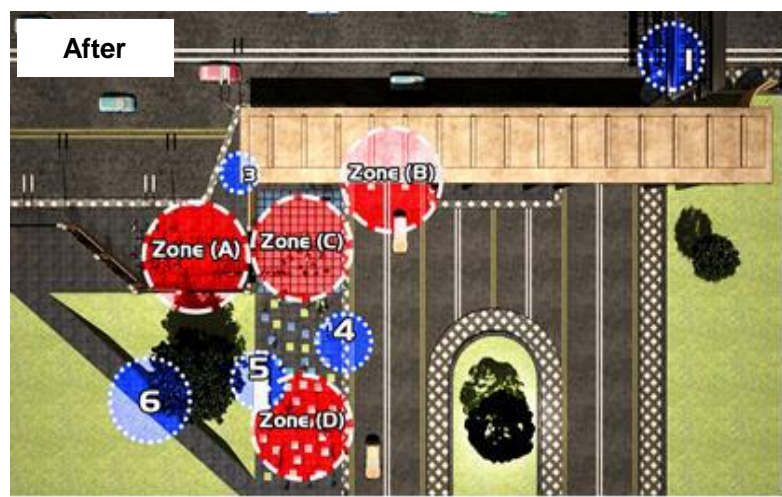

We are adding six integrated ideas as a redesign proposal to convert this gate to a sustainable one:
1. LED signage
4. LED lights
2. LED Screen
5. Smart seating
3. Bluetooth Cameras
6. New footpath

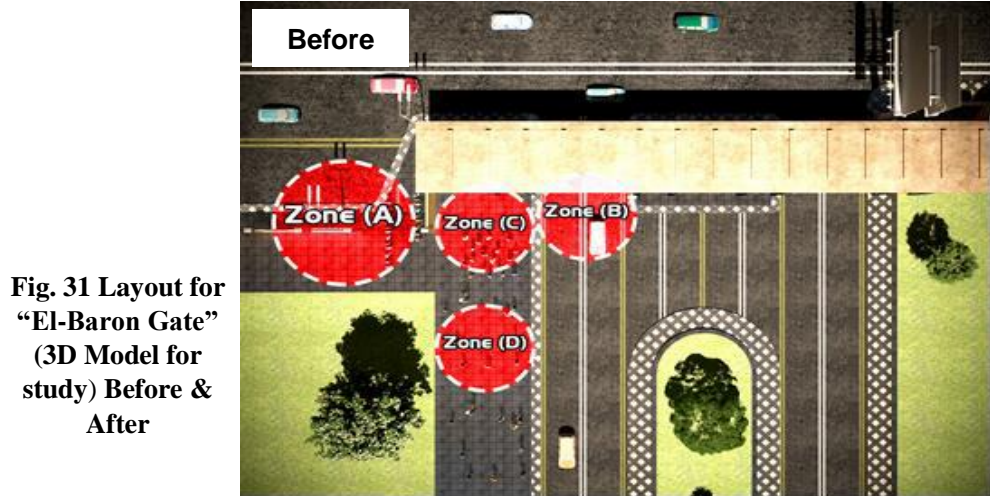




\section{ZONES STUDY}

(Fig.31, 32, 33, 34).

Zone (A): Changing the fence path to make a lobby in zone(c) because now people enter in a path not in a gathering space. This idea will make a suitable area inside and outside the entrance to accommodate with overcrowding in rush hours. We took the path behind the entrance and added this to the front of the entrance to increase its area and make another path after zone (D).

Zone (B): Main cars entrance we will add 6 tiles of piezoelectric pads which put in cars way to generate power as we explain before. We talk here about 5.000 car as an average per day will cross above this tiles and generate power.

Zone $(\boldsymbol{C})$ : This is the most important zone in our proposal, this area is $100 \mathrm{~m} 2$. Which more than 30.000 person cross from every day in an average 10 hours per day. So we will cover this with SEF. For walking, SEF is more suitable, it is designed for this kind of movement. The

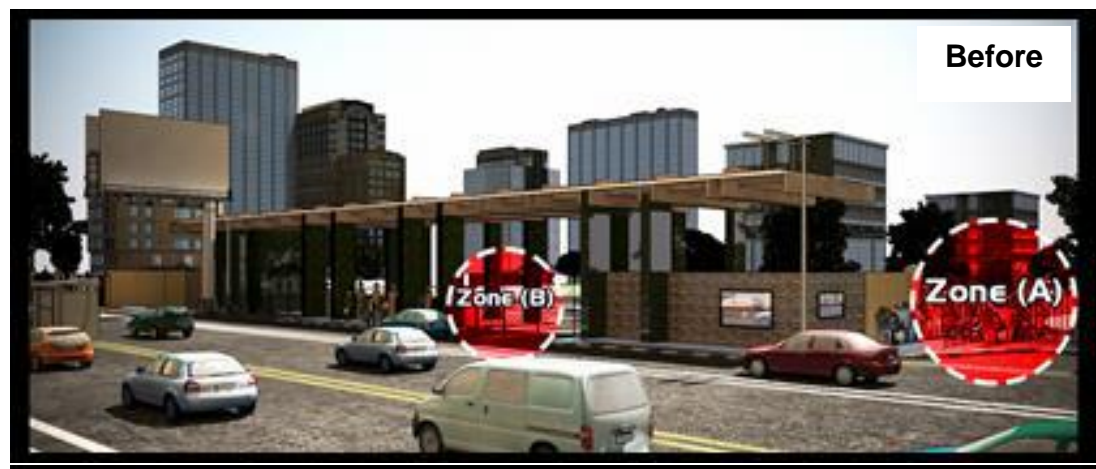
power is calculated as:

- Number of tiles $=100 \mathrm{~m} 2 /\left(.75^{*} .75\right)=177$ tiles

- $\underline{\text { Power }=30.000}$ person $* 177 \mathrm{SEF}$ tiles $* 7$ Joule per step $=37.17 \mathrm{MJ}=37.17 \mathrm{MJ} / 3.6=10.325 \mathrm{KWh}$

Zone $(\boldsymbol{D})$ : Main footpath, in our proposal we put 50 random tiles of Pavegen tiles with different natural recycled map. The energy harvested from Pavegen tiles can be used to power low-voltage local applications. The greater the footfall, the larger the number of tiles, the more Pavegen can power.

\section{IDEAS STUDY}

Power $=30.000$ person $* 50$ Pavegen tiles $* 7$ Joule per step $=10.5 \mathrm{MJ}=10.5 \mathrm{MJ} / 3.6=2.9 \mathrm{KWh}$

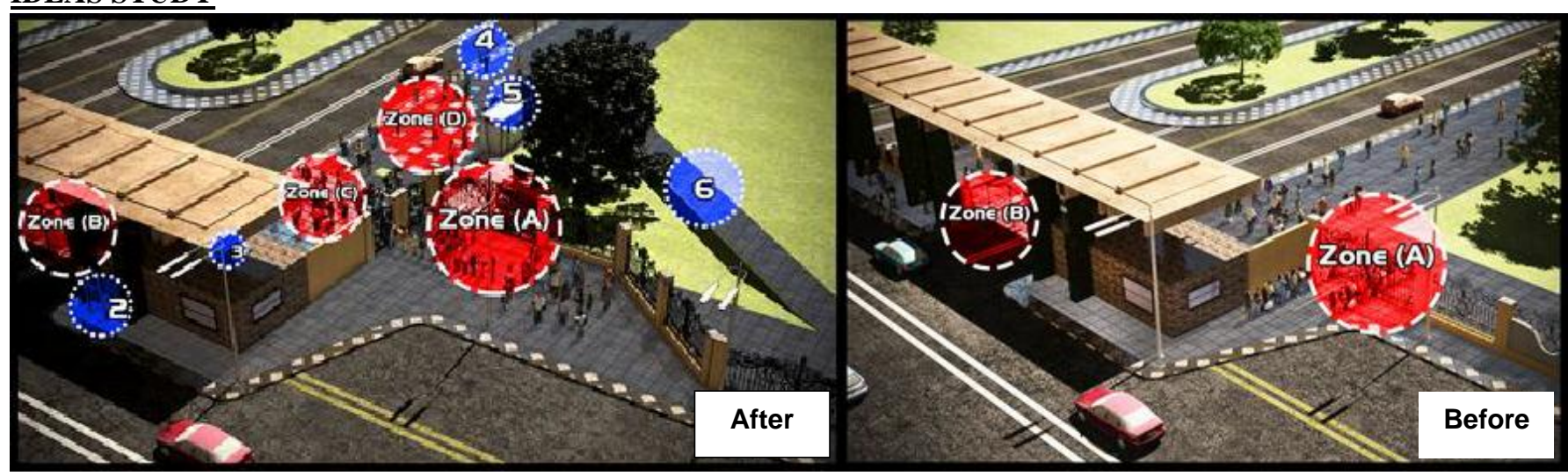

Fig. 33 Bird eye for "El-Baron Gate" (3D Model for study) Before \& After

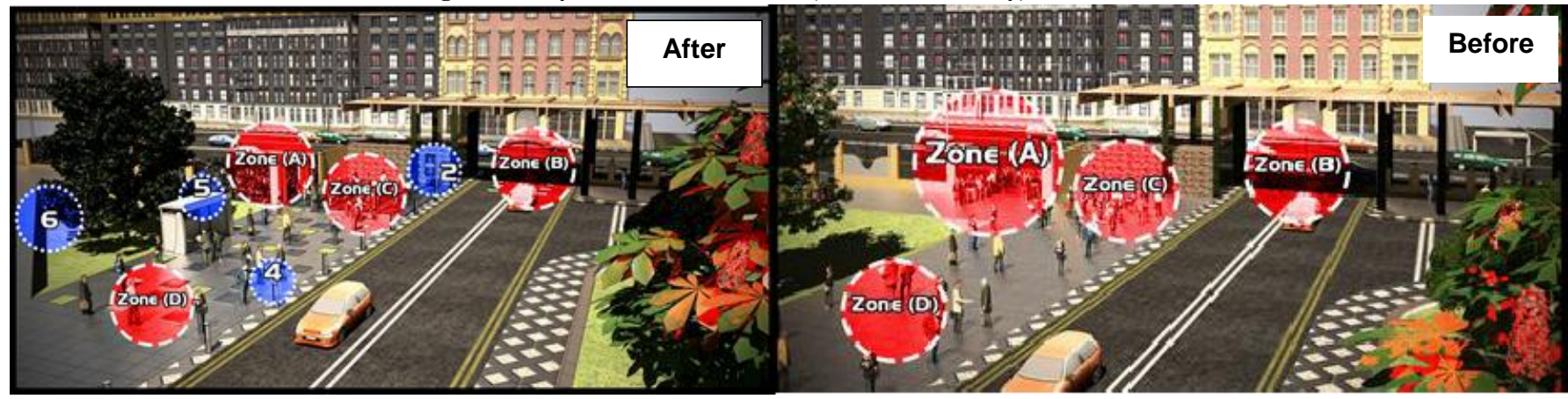

Fig. 34 Bird eye for "El-Baron Gate" (3D Model for study) Before \& After 


\section{ARCHITECTURE IN CROWD FARMS: RELATION BETWEEN HUMAN AND ENERGY}

The energy harvested from different types of tiles can be used to power low-voltage local applications such as lighting, advertisement displays, wireless systems and way finding lighting solutions.

1. LED signage: Self lighting from saving the energy generated from tiles and reusing it in advertising.

2. LED Screen: Screen shows in it number of people which enter the university every day and the amount of power generated from them to raise awareness.

3. Bluetooth Cameras: Cameras and Wi-Fi spots work with generated power from people.

4. LED lights: with a sensor, for lighting on demand by using generated power also.

5. Smart Seating: sustainable seating which contain Wi-Fi spots and all of this fixtures use human power which generated from kinetic energy of people.

6. New footpath: We added this path to serve users in the lift side of the university (Fig.35, 36).

\section{CONCLUSION}

Results of our applications met that we can generate more than $15 \mathrm{KWh}$ every day from only one (Entering) entrance of the University and we can double the amount of generated power to $30 \mathrm{KWh}$ every day by doing the same to the exiting area in the same gate. We can also dissemination the experience to all of university entrances to increase the amount of generated power from human crowd farms. For example, the generated amount from only one day can be used in (Fig.37):

- Power a connected system of $100 \mathrm{~W}$ for 150 hours

- Power device or something of $1 \mathrm{~kW}$ for 15 hours

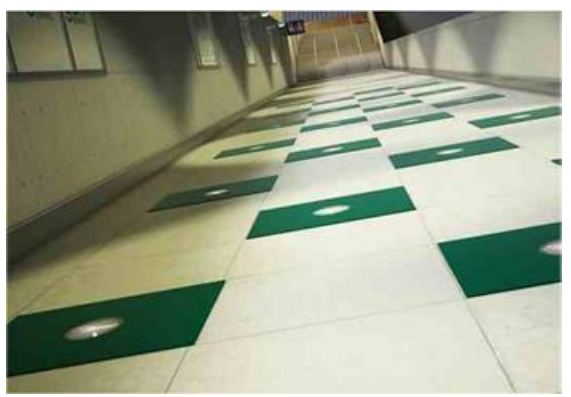

Fig. 35 The Pavegen Tiles in footpath [7]

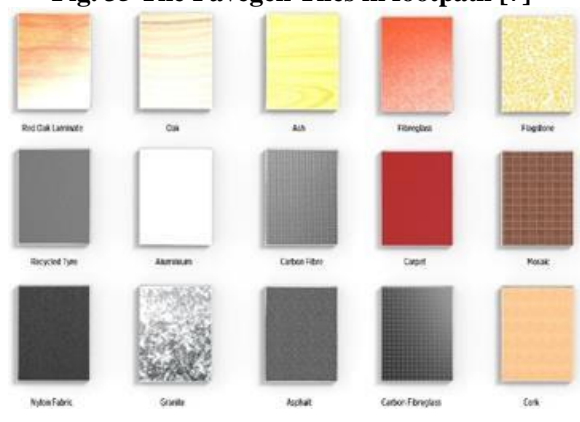

Fig. 36 The Pavegen Tiles customized cover

- Power 1095 computers for a full day

- Power 37 computers for a month

high-performing energy system. Choosing inaction today is likely to result in deeper challenges in the future. Successful energy reform is as much about implementation as it is about effective design - strong governance, market effectiveness and public engagement are fundamental. Governments architecting the future energy transition along these principles will

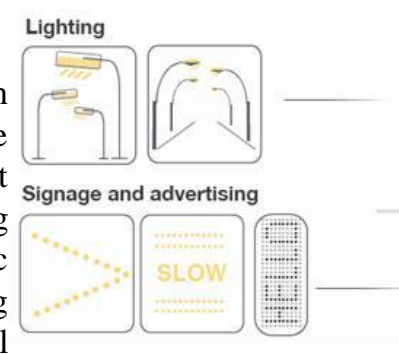
reap the rewards in the long term. When we care about this new sustainable and renewable resource of energy, it'll make a lot of differences in urban design standards. We look forward to make the reason of the energy problem and pollution (human) to be one of the main reasons to solve the problem. Finally, it's not only a new field of research; it's more than a new vision for our life and our future.

\section{Recommendations}

Considering the measured harvested power levels, it should be taken into account that a further energy saving is apparent, when comparing this dance floor to gridconnected devices, due to the lack of electric transmission losses. However, arguably more important, this dance floor has increased the public awareness by visualizing power from the people to the clubbing public. This visualization, co mbined with a generating experience, is a very important factor to let young people understand what energy generation comprehends, and the finite energy resources ultimately make people to use energy with much more care. Social and environmental issues are worldwide and will always demand attention. As such, sustainability is more the beginning of a new corporate attitude or lifestyle than a dying trend. Numerous examples exist, and companies working on their sustainability are very profitable, e.g., due to loyalty and motivation of employees, loyalty of customers, imagination, and innovation. Therefore, in addition to club environments, improved systems are being developed that unnoticeably harvest or steal power from the people for application within train stations, busy traffic intersections, and airports. Governments all over the world especially in development countries should to take steps to solve its energy and population issues with dealing with human. We suggest to make an evaluation system for public building or spaces to give the license for these buildings if it's put human factor in these designs and urban to encourage in interesting in this new field of power (Fig.38). 


\section{REFERENCES}

1. The Egyptian ministry of electricity and energy website, Annual reports, http://www.moee.gov.eg

2. WEF (world economic forum), "Future Of Electricity" Report, January 2015. www3.weforum.org

3. Sustainable Dance club B.V. Pannekoekstraat, Rotterdam, The Netherlands. [Online]. Available: http://www.sustainabledanceclub.com.

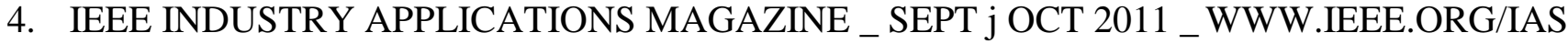

5. [Online]. Available: http://www.sustainabledanceclub.com

6. http://inhabitat.com/tokyo-subway-stations-get-piezoelectric-floors/japan-east-rail-corporation-jr-eastpiezoelectric-floors-energy-generating-floors- human-powered-motion-passengers-power-trainstation-2/\#ixzz3aqin1UtU

7. http://inhabitat.com/award-winning-pavegen-floor-tiles-will-use-energy-from-footsteps-to-light-up-ukshopping-center/

8. http://www.pavegen.com/home

9. http://inhabitat.com/new-piezoelectric-railways-harvest-energy-from-passingtrains/innowattech3/\#ixzz3aqpwCF27

10. http://www.mans.edu.eg/

11. G. A. Brooks, T. D. Fahey, and K. M. Baldwin, Exercise Physiology, Human Bioenergetics and Its Applications. Boston: McGraw-Hill, 2005.

12. J. Donelan, Q. Li, V. Naing, J. Hoffer, D. Weber, and A. Kuo,

13. "Biomechanical energy harvesting: Generating electricity during, walking with minimal user effort," Science, vol. 319, pp. 807-810, 2008.

14. J. A. Paradiso and T. Starner, "Energy scavenging for mobile and wireless electronics," IEEE Pervas. Comput., vol. 4, no. 18, pp. 18-27, 2005.

15. L. Rome, L. Flynn, E. Goldman, and T. Yoo, "Generating electricity while walking with loads," Science, vol. 309, pp. 1725-1728, 2005.

16. J. Paradiso and T. Starner, "Energy scavenging for mobile and wireless electronics," IEEE Pervas. Comput., vol. 4, no. 1, pp. 18-27, 2005.

17. John Holdren, 1991). https://www.masterresource.org/masterresource/energy-as-master-resource-ii-foes-agree/

18. WEF_GlobalRisks_Report_2014, http://www.weforum.org/reports/global-risks-2014-report

19. John P. Holdren,Population and the Energy Problem, University of California (Berkeley), http://www.geo.arizona.edu/geo4xx/geos478/2009/Resources/Holdre n91_Pop.Energy_Pop.Env.pdf

20. (WEF_GlobalRisks_Report_2015) The Future of Electricity, http://www.weforum.org/reports 